\title{
BMJ Open A woman's place is in theatre: women's perceptions and experiences of working in surgery from the Association of Surgeons of Great Britain and Ireland women in surgery working group
}

\author{
Maria Irene Bellini, ${ }^{1}$ Yitka Graham, ${ }^{2,3}$ Catherine Hayes, ${ }^{2}$ Roxanna Zakeri, ${ }^{4}$ \\ Rowan Parks, ${ }^{5,6}$ Vassilios Papalois ${ }^{1,7}$
}

To cite: Bellini Ml, Graham Y, Hayes $\mathrm{C}$, et al. A woman's place is in theatre: women's perceptions and experiences of working in surgery from the Association of Surgeons of Great Britain and Ireland women in surgery working group. BMJ Open 2019;9:e024349. doi:10.1136/ bmjopen-2018-024349

- Prepublication history for this paper is available online. To view these files, please visit the journal online (http://dx.doi. org/10.1136/bmjopen-2018024349).

Received 7 June 2018 Revised 17 October 2018 Accepted 26 October 2018

Check for updates

(c) Author(s) (or their employer(s)) 2019. Re-use permitted under CC BY-NC. No commercial re-use. See rights and permissions. Published by BMJ.

For numbered affiliations see end of article.

Correspondence to

Dr Maria Irene Bellini;

mariairene.bellini@nhs.net

\section{ABSTRACT}

Objective Surgery remains an inherently male-dominated profession. The aim of this study was to survey women working within the discipline, to understand their current perceptions, providing insight into their practical day-to-day lives, supporting an action-oriented change.

Design and setting The link to a confidential, online survey was distributed through the Association of Surgeons of Great Britain and Ireland (ASGBI) social media platforms on Facebook and Twitter over a 2-week period in October 2017. Participants Women working in surgical specialties and actively responding to the link shared through the ASGBI social media platforms. No patients were involved in the study. Primary and secondary outcome measures Data were analysed through a mixed-methods approach. The quantitative data were analysed through descriptive statistics and qualitative analysis was undertaken using a constant comparative analysis of the participants' comments, to identify salient patterns (themes).

Results A total of 81 female participants replied (42\% response rate based on the Facebook group members), with $88 \%(n=71)$ perceiving surgery as a male-dominated field. Over half had experienced discrimination $(59 \%, n=47)$, while $22 \%(n=18)$ perceived a 'glass ceiling' in surgical training. Orthopaedics was reported as the most sexist surgical specialty by $53 \%(n=43)$. Accounts of gendered language in the workplace were reported by $59 \%(n=47)$, with $32 \%$ $(n=25)$ of surveys participants having used it. Overall, a lack of formal mentorship, inflexibility towards part-time careers, gender stereotypes and poor work-life balance were the main perceived barriers for women in surgical careers.

Conclusion These findings highlight the implicit nature of the perceived discrimination that women report in their surgical careers. The ASGBI acknowledges these perceptual issues and relative implications as the first of many steps to create an action-oriented change by allowing all staff, regardless of gender, to reflect on their own behaviour, perceptions and the culture in which they work.

\section{INTRODUCTION}

Despite annual intakes of medical school cohorts evidencing a $55 \%$ female contingent,
Strengths and limitations of this study

- This study adopted a multiple methods approach with the qualitative elements enriching the quantitative data on the topics addressed.

- The nature of the survey allowed critical introspection with a useful insight to create the action-oriented change.

- The representativeness and transferability of the data are hindered by the probability that women who had encountered discrimination were more likely to respond to this survey.

- As an online survey, it was not possible to probe to gain a deeper understanding of the comments.

only $28 \%$ of these women eventually pursue a career in surgery via higher surgical training in the UK. ${ }^{1}$ Beyond these baseline figures, a qualitative analysis of the factors deterring women from pursuing surgery as a career in the Western countries is needed to understand more in depth the nature of these hidden barriers. ${ }^{2}$

In reality, several extraneous variables rooted in sociocultural backgrounds, such as toy makers sometimes blatantly but more often inadvertently, discourage girls from studying science, technology, engineering and mathematics (STEM), ${ }^{3}$ as do some of their teachers. ${ }^{45}$ It is evident that some girls lack role models in these fields and grow up with the unfounded presupposition they would not do well in those, considered male and technical professions. ${ }^{6}$ This ultimately influences their intrinsic motivation and their resultant capacity to succeed in fields like surgery, due to the perception that these careers require self-selected individuals who are driven, competitive and able to endure years of intense schooling and high expectations. $^{7}$ 
Although there is acknowledgement of the longstanding historical contribution to surgical practice from women $^{89}$ the manner in which women feel perceived by their male counterparts is under evidenced and little reported. The key aim of this study is then to capture the perceived barriers in the experiences of women working within the field of surgery and to use them as a source of reflection for surgical staff of either gender, for policy-makers and for professional bodies such as the Association of Surgeons of Great Britain and Ireland (ASGBI). Acknowledging these issues is the first of many steps to addressing their implication and to help moving beyond tokenism in the coconstruction of relevant, impactful and evidence-based action. ${ }^{10}$

\section{METHODS}

The link to a voluntary, confidential, online survey was distributed through the ASGBI women in surgery social media platforms of Facebook (191 members) and shared via Twitter for a 2-week period in October 2017. Weekly reminders were posted. The Facebook site $^{11}$ is a closed group composed of healthcare professionals working in the field of surgery. It is mainly composed by women (90\%), aged between $25-34$ years $(39 \%)$ and $35-44$ years $(30 \%)$. The main origin country is the UK $(70 \%)$, with also contribution from India, Pakistan, USA, Europe and Africa.

The questions were designed to understand whether barriers exist to deter women from pursuing surgery as a career, and if so, what these barriers are and what interventions would be suggested in order to reduce them. Respondents were encouraged to provide their personal opinions throughout the free-text boxes after each question. As the aim of the research was to obtain as many responses as possible, while understanding the participants' experiences of being a female working in surgery, a mixed-methods approach was used. The quantitative data were analysed through descriptive statistics, and to provide context to this data and more fully explore the participants' responses, a qualitative approach was taken using constant comparative analysis of the participants' comments, to identify patterns (themes) within the responses. This was guided by the principles of thematic analysis, ${ }^{12}$ using a six-step process of data familiarisation, generating initial codes, searching for themes, reviewing themes, defining and naming themes and producing the report.

Given the sensitivity of the topic, the closed access to the social media platforms, and the wish to ensure honest, open responses and anonymity, no demographic information was collected.

\section{Patient and public involvement}

No patients were involved in the study.

\section{RESULTS}

A total of 81 participants completed the survey, an estimated response rate of $42 \%$ based on the Facebook group membership. It was not possible to determine how the Twitter platform influenced response rate.

\section{Quantitative analysis}

The $88 \%(\mathrm{n}=71)$ felt that surgery remains a male-dominated field, with $59 \%(\mathrm{n}=47)$ reporting or witnessing discrimination against females in the workplace. The hidden barriers for women reported by $34 \% \quad(n=28)$ were that the profession was not conducive to motherhood and family life, with $16 \%(\mathrm{n}=13)$ citing childcare issues. There was a perception that the surgical profession and culture was male oriented, conceptualised as an 'old boys club' $(16 \%, \mathrm{n}=33)$ and possessing a masculine attitude and negative bias $(13 \%, n=9)$. The framework for a career in surgery was reported as lacking flexibility and part-time careers $(12 \%, \mathrm{n}=10)$, with $10 \%(\mathrm{n}=8)$ citing unsocial hours and working patterns (see table 1).

The concept of a 'glass ceiling' for women within the surgical profession was raised, with $44 \% \quad(n=36)$ feeling this did not exist. All 81 participants answered this question, with $21 \%(\mathrm{n}=17)$ feeling there was a tangible glass ceiling. The remaining $35 \% \quad(n=28)$ chose not to comment.

Respondents were also asked if a glass ceiling existed at any particular levels during surgical training, with $9 \%$ $(n=7)$ stating that this was evident at all levels; $6 \%(n=5)$ referred women under-representation at consultant role with different treatment compared with males.

Given the lack of women in surgical careers, participants were asked to comment on why women may be attracted to other clinical specialties. The most frequent responses $(26 \%, \mathrm{n}=21)$ were quality of life/work-life balance and less unsocial hours $(15 \%, \mathrm{n}=12)$ (see table 2$)$.

When asked what could be done to attract more women to the surgical professions, nearly half $(42 \%, n=34)$ cited improved quality of life, and flexibility in part-time pathways with career and training options (see table 3 ).

Although there is existing support for women in surgery, such as less than full-time (LTFT) training and maternity leave, the dearth of women in surgical professions may demonstrate that there is a need for additional support mechanisms. Over $30 \%$ of respondents felt that LTFT training was perceived negatively, and this needed to be addressed. There was also a reported need to reduce stigma associated with women taking career breaks $(22 \%$, $\mathrm{n}=18$ ) and to increase understanding of the impact of family on day-to-day activities $(18 \%, \mathrm{n}=15)$ in surgical practice (see table 4 ).

To further explore the perceptions of a male-dominated surgical culture, participants were asked to list the specialties in which this dominated. More than half $(53 \%, \mathrm{n}=43)$ felt that trauma and orthopaedics was a sexist specialty, followed by cardiothoracic $(16 \%, \mathrm{n}=13)$ and general surgery $(15 \%, \mathrm{n}=12)$, with $15 \%$ reporting no surgical specialty as being more sexist than another (see table 5).

Over half of respondents $(58 \%, \mathrm{n}=47)$ felt that gendered language exists within surgery. A quarter of the 
Table 1 Participant-perceived barriers to a career in surgery

\begin{tabular}{ll}
\hline Barrier & Response, \% (n) \\
\hline $\begin{array}{l}\text { Not a profession conducive with } \\
\text { motherhood, family and children }\end{array}$ & $34(28)$ \\
\hline $\begin{array}{l}\text { Childcare issues } \\
\text { 'Old boys' club/network }\end{array}$ & $16(13)$ \\
$\begin{array}{ll}\text { Male attitudes/bias } \\
\text { Culture of surgery as a masculine }\end{array}$ & $13(13)$ \\
field & $12(10)$ \\
$\begin{array}{l}\text { Unconscious bias } \\
\text { Lack of flexible/part-time training }\end{array}$ & $12(10)$ \\
$\begin{array}{l}\text { Unsocial hours/working patterns/ } \\
\text { rotas }\end{array}$ & $10(8)$
\end{tabular}

$\begin{array}{ll}\begin{array}{l}\text { Perceptions by nurses and patients } \\ \text { that women are not able to be }\end{array} & 7(6) \\ \text { surgeons } & 6(5) \\ \text { Maternity leave/career break } & 6(5) \\ \begin{array}{l}\text { Women are excluded from 'male- } \\ \text { only' social events }\end{array} & 5(4) \\ \begin{array}{l}\text { Women less confident in their abilities } \\ \text { Lack of female role models }\end{array} & 5(4) \\ \begin{array}{l}\text { Men have more variety in surgical } \\ \text { career choices }\end{array} & 5(4) \\ \begin{array}{l}\text { Male surgeons behaving } \\ \text { inappropriately }\end{array} & 4(3) \\ \begin{array}{l}\text { Patients prefer male surgeons } \\ \text { Image of female surgeons as being }\end{array} & 2(2) \\ \text { on par with a nurse } & \end{array}$

Perceptions that women will want a 2 (2) less onerous career

\begin{tabular}{ll} 
Social barriers & $2(2)$ \\
\hline Barriers are explicit, not hidden & $2(2)$ \\
\hline Lack of flexibility & $2(2)$ \\
$\begin{array}{l}\text { Women need to be seen as ruthless } \\
\text { in order to succeed }\end{array}$ & $2(2)$ \\
$\begin{array}{l}\text { Women need to pull their weight like } \\
\text { a man }\end{array}$ & $2(2)$
\end{tabular}

Hard for women to establish a private (1) practice

\section{Personal expectations}

Historical/traditional expectations of women

\begin{tabular}{ll} 
No barriers & $4(3)$ \\
Respondent skipped question & $7(6)$ \\
\hline
\end{tabular}

respondents confessed to having used gendered language themselves, but over half $(52 \%, n=41)$ had not used it, with gendered language not affecting career choices for $87 \%$ ( $\mathrm{n}=70 \%$ ). The most common method of challenging gendered language was to speak out/correct and state
Table 2 Benefits of working in non-surgical specialties for women

Quality of life/flexibility/work and life $26 \%(n=21)$

balance

\begin{tabular}{ll}
$\begin{array}{l}\text { More accepting of part-time/less } \\
\text { than full-time training }\end{array}$ & $17 \%(n=14)$ \\
$\begin{array}{l}\text { Less unsocial hours } \\
\text { More role models/mentoring }\end{array}$ & $15 \%(n=12)$ \\
$\begin{array}{l}\text { Accepting of childcare and family } \\
\text { commitments }\end{array}$ & $10 \%(n=12)$ \\
\hline $\begin{array}{l}\text { Less macho/male attitudes } \\
\text { Less on call }\end{array}$ & $7 \%(n=6)$ \\
\hline $\begin{array}{l}\text { Less intimidating reputation/less } \\
\text { competitive }\end{array}$ & $7 \%(n=6)$ \\
Other & $21 \%(n=5)$ \\
Not sure/do not know & $16 \%(n=13)$ \\
Respondent skipped question & $7 \%(n=6)$
\end{tabular}

inappropriate language $(30 \%, \mathrm{n}=24)$, but $18 \% \quad(\mathrm{n}=15)$ had not encountered any incidences (see table 6).

When asked what advice they would give to others when encountering gendered language, the most common recommendation was to confront or speak to the person $(51 \%, n=41)$, with $17 \%(n=14)$ advising correction of the language used (see table 7 ).

\section{Thematic analysis}

There was an overarching theme of participants feeling constrained within the present surgical environment,

Table 3 What could surgery do to attract more women to the profession

Flexible training and career options (eg, $42 \%(n=34)$ part time, less than full time)

Project a less masculine image/address $25 \%(n=20)$ this

\begin{tabular}{ll} 
Improve the work/life balance & $18 \%(n=15)$ \\
\hline More female mentors/role models & $18 \%(n=15)$ \\
\hline More team/collaborative approaches & $7 \%(n=6)$ \\
\hline Financial support of trainees & $6 \%(n=5)$ \\
$\begin{array}{l}\text { Remove the perception of the need for } \\
\text { PhDs/to be an academic }\end{array}$ & $3 \%(n=3)$
\end{tabular}

$\mathrm{PhDs} /$ to be an academic

\begin{tabular}{ll} 
Sessional work & $2 \%(n=2)$ \\
\hline More positions in larger cities & $2 \%(n=2)$ \\
\hline Less overbooking & $1 \%(n=2)$ \\
\hline $\begin{array}{l}\text { More surgical training for medical } \\
\text { students }\end{array}$ & $1 \%(n=1)$ \\
\hline Educate surgeons in unconscious bias & $1 \%(n=1)$ \\
\hline Nothing & $3 \%(n=3)$ \\
\hline Do not know/not sure & $5 \%(n=5)$ \\
\hline Respondent skipped question & $6 \%(n=5)$ \\
\hline
\end{tabular}


Table 4 What other support (aside from less than full time (LTFT) and maternity leave) is needed for women in surgery

\begin{tabular}{ll} 
Change the negative perceptions of LTFT & $32 \%(n=26)$ \\
$\begin{array}{l}\text { Reduce the perceived stigma associated with women who } \\
\text { take career breaks }\end{array}$ & $22 \%(n=18)$ \\
$\begin{array}{l}\text { Increase understanding of the perceived impact of family } \\
\text { on day to day work activities and support this }\end{array}$ & $18 \%(n=15)$ \\
\hline Encourage men to take LTFT & $15 \%(n=12)$ \\
Career break & $13 \%(n=11)$ \\
On-site childcare & $7 \%(n=6)$ \\
\hline $\begin{array}{l}\text { More awareness and promotion of rules, regulations and } \\
\text { support of gender equality and support for women }\end{array}$ & $6 \%(n=5)$ \\
Nothing needed & $6 \%(n=5)$ \\
Modular training & $6 \%(n=5)$ \\
Other & $26 \%(n=21)$ \\
Not sure & $13 \%(n=11)$ \\
\hline
\end{tabular}

which appears to be better equipped to support males, with sociocultural norms embedded in masculine discourses. The participants appeared to make efforts to fit into the environment, adapting a variety of stances to do this. The constraints were conceptualised as conflicting personal and career decisions, under-representation, a relative rigidity in surgical career structures and the process of discrimination, both active and nuanced (self and others), that exists in current surgical practice. These themes are supported by in vivo quotes from the data:

Conflict between personal and career decisions

'Trainees have families and other responsibilities to manage as well as surgical training'

'At registrar level, many women switch to GP training for family reasons'

'Maybe there is a glass ceiling, as the training scheme is long. When you want to have a family you are at senior level for jobs. It is harder to stay focused on

\begin{tabular}{ll}
\hline Table 5 & Participant reported sexist surgical specialties \\
\hline Surgical specialty & $\begin{array}{l}\text { Responses, \% } \\
\text { (n) }\end{array}$ \\
\hline Orthopaedics/trauma & $53(43)$ \\
Cardiothoracic & $16(13)$ \\
General surgery & $15(12)$ \\
Urology & $5(4)$ \\
None & $4(3)$ \\
\hline Vascular & $4(3)$ \\
\hline Neurosurgery & $4(3)$ \\
\hline Hepatobiliary & $(1)$ \\
\hline Plastics & $(1)$ \\
\hline All & $(1)$ \\
\hline Leading question & $(1)$ \\
\hline Skipped question & $11(9)$ \\
\hline Not sure/do not know & $15(12)$ \\
\hline
\end{tabular}

Table 6 Challenging sexist language in the workplace

\begin{tabular}{ll}
\hline Action & Response, \% (n) \\
\hline $\begin{array}{l}\text { Speaking up/correcting/stating } \\
\text { inappropriate language }\end{array}$ & $30(24)$ \\
\hline Not experienced sexist language & $18(15)$ \\
Humour & $9(7)$ \\
Find it difficult & $7(6)$ \\
$\begin{array}{l}\text { Non-confrontational approach/social } \\
\text { media }\end{array}$ & $2(2)$ \\
Not able to interpret response & $10(8)$ \\
\hline Ignore/refuse to respond & $7(6)$ \\
\hline
\end{tabular}

career and your curriculum vitae (CV). This affects the quality of your CV at interview for consultancy. Somehow, it's easier for wives to follow their surgeon husbands rather than for husbands to follow surgeon wives'

'I am horrified by the stories of women in the first trimester of pregnancy with morning sickness vomiting several times between procedures during a list, and women in the third trimester doing nights, etc., especially when they want to switch to a less physically intense session'

\section{Under-representation}

'Up until recently, there were no women in my sub-specialty'

'Now that I am a consultant, I feel massively in the minority'

Table 7 Advice to colleagues on dealing with sexist language in workplace environments

Advice

\begin{tabular}{ll}
\hline Confront/speak to person involved & $51(41)$ \\
\hline Correct the language used & $17(14)$ \\
\hline Respondent did not answer & $12(10)$ \\
\hline Deflect using humour & $11(9)$ \\
Do not accept/remain silent & $10(8)$ \\
lgnore & $9(7)$ \\
Be aware that people may not be aware & $7(6)$ \\
they are using sexist language/do not & \\
make an issue out of it (unless 'over the & \\
line')/do not be overly sensitive & \\
Seek support from others/support others & $7(6)$ \\
File complaint & $3(2)$ \\
Demand apology & $(1)$ \\
\hline Treat as bullying & $(1)$ \\
\hline Do not know/no advice & $4(3)$
\end{tabular}


Rigidity in surgical career structures

'Reduce the hierarchal nature of surgical training; this would improve safety and morale for all'

'There needs to be a real understanding that having a small child really hinders the ability to do things like extra work that needs to be completed out of hours. If there was a way to come back into training but have a pause on in counting towards your time up then there would be less financial and timescale stress'

'Flexible training and to stop having such rigid pathways to CCT (Certificates of Completion of Training), different paths are ok and valid. We also need true competency based training - some people will complete faster than $5 / 6$ years, others might need longer. Be more open to time out.'

'There's an implicit assumption that surgeons will be able to have their families trail around the country after them for jobs and fellowships. Realistically this is less possible for women with professional partners and small children. Women are presumed to deskill during maternity leave and discouraged from working part-time.'

\section{Discrimination: self}

'Generally, women are less confident in their abilities, whereas men are more confident...often holds females back'

'Some women try and take advantage way over expected norms and use it to bargain for favours which make things worse'

\section{Discrimination: others}

'People see a glass ceiling, actually you can get in, but you are treated differently, so really a glass cliff'

'You're an unlikely looking orthopod'

'I find the surprise and confusion and refusal to believe I'm an orthopod for example, 'you're too nice to be an orthopod' and 'that's not something to be proud of' very frustrating'

'I recently presented a paper at a plenary session at a UK surgical meeting. I was the only female presenter. I got equal marks as the top male candidate (announced at the podium by the head of the society) but the prize was given to the male and the prize was a tie'

'I have done the World Health Organization checklist and then had the comment 'we need to wait for the surgeon' despite having introduced myself as the surgeon'

'I got told by another surgeon that he left vascular surgery for plastics because there were 'too many women surgeons and they caused too much drama'.

There were reported accounts of patients using gendered language with implicit assumptions that female surgeons were not acceptable, or that being female was not associated with being a surgeon.

'Patients don't think women can be doctors, let alone surgeons'

'Significantly more patients call me nurse or lady doctor than any of my colleagues'

'Patients are often shocked that I will be doing their operation, and I have led ward rounds where the patients have talked to my tall male F1 and not me'

'Patients are extraordinarily sexist for example, patients have walked into a consulting room and said to me 'I thought I would be seeing a doctor at least' before I had time to introduce myself. I am 34 and been a doctor for 10 years'

\section{Perceived implicit discrimination was reported, but could not be proven}

'I had difficulty trying to get a consultant job. Although I was already working as a locum consultant, I lost out many times to younger men who were all registrars. Various reasons were cited, but I did begin to wonder if my face didn't fit. Until a couple of years ago, there were no women in my particular subspecialty'

'Improve the stigma that is sometimes attached to women who choose to take time out of their careers for children. Many women I've spoken to say they aren't viewed as competent as their full time colleagues'

'We lose out on consultant posts to younger males'

In the physical workplace, there was an account of discrimination

'I am the only female Consultant General Surgeon in my Trust. I'm not allowed in the consultant changing room. There is one consultant changing room and it is for men only'

\section{Accounts of discrimination were supported by other healthcare} staff

'Theatre staff have commented that male surgeons get more opportunities in theatre than female'

There were also reports of female surgeons being discriminated against by other non-surgical staff

'The secretaries in my Trust do not do as much for the female consultants as they are perceived as having taken a 'man's job.'

\section{DISCUSSION}

This survey, conducted through the ASGBI social media platforms, illuminates the lived realities of female surgeons in the UK today. Gender bias and discrimination were reported by $59 \%$ of the participants irrespective of level of training and experience, suggesting an ancient culture pervading our society since the 1800 s, at 
the time of the first female surgeon in the UK, Elizabeth Garrett. ${ }^{1314}$

The greatest perceived barrier to women wanting to pursue and persist with a career in surgery was incongruity with motherhood and childcare commitments $(50 \%)$. Literature reports a significant level of attrition for women in surgical training, ${ }^{15}$ traditionally seen as one of the most competitive and time-consuming specialties ${ }^{16}$ with the perception that spending less time in surgical training would compromise competency achievement. ${ }^{17}$ Furthermore, there is discrepancy on parental leave policies across hospital trusts and specialties, despite widespread recognition that better support for parents engenders marked benefits for the health and well-being of doctors, their children and ultimately healthcare provision. ${ }^{18}$ The general perception is that family-friendliness may be hard to reconcile with the working requirements of the surgical specialty, often involving patient treatment of unknown length or at unsocial times of day or night. ${ }^{19}$ There is a challenge to manage work in these areas and to improve family-friendliness without compromising patient care. This lack of support is potentially leading to burn out, since we know that this is ultimately driven by external factors such as excessive working hours, workload and conflicts with family commitments. ${ }^{13} 14$ Thus, for some women, the only perceived option to preserve their own mental health is represented by withdrawing from surgical training.

How do we create the change needed? Encouraging and tangible signs of an already emergent cultural change, like day-care facilities and childcare options, are reflected in the wider societal acknowledgement of women in surgery. One example is the New Year's Honours List, where the Royal College of Surgeons of England past president, and first female president, Clare Marx, received a damehood in acknowledgement of her contribution to surgical practice. In addition to this, Jackie Taylor has been chosen as president-elect of the Royal College of Physicians and Surgeons of Glasgow for the first time in its 418-year history, where, for the first time, there is also a female surgical vice-president, Alison Lannigan. While these women are atypical and not necessarily representative of all women in surgery, they act as positive role models for women in the context of career progression. We need strategic encouragement and education about the realities of leadership roles in STEM, along with instigation of evidence-based and effective schemes for gender equality in the workplace, such as the ATHENA SWAN for academic careers. ${ }^{20}$

Visibility of role models is key to increasing current female training rates and public advocacy campaigns through social media facilitate education and awareness of culturally sensitive matters. To this end, the ASGBI launched a Facebook group ${ }^{11}$ to bring individuals together for networking and communications about women in surgery, parenting and work-life balance. ${ }^{11}$ As primary communication methods, social media are increasingly integrated into the daily routine of individuals personal activity and practice, with $68 \%$ of women and $62 \%$ of men using them. ${ }^{21}$ We aim to be what we see or what we deal with in our daily practice. ${ }^{22}$ The ASGBI \#HowIBecameAWomanInSurgery' campaign was created on this basis to shine light on the journey through the training pathways of female surgeons. Since much of a culture is underpinned and shaped by the language used, ${ }^{23}$ we advocate for a cultural identification with women becoming surgeons. Sharing the journeys of successful female surgeons aims to inspire and support other members, allowing them to see how frequently encountered barriers were overcome from different perspectives. ${ }^{24}$ Evidence of the benefits of mentoring to support women as they progress in their careers is plentiful. ${ }^{25}$ Interestingly, this survey revealed great awareness of the benefits of mentoring among female surgeons, but a view in $15 \%$ that it currently remains an advantage to be gained primarily in non-surgical specialties. The lack of female role models in surgical leadership and consultancy positions contribute to the perpetration of the white male stereotypical gender role, and those who do not fulfil these characteristics, may believe they cannot make in this environment. ${ }^{22}{ }^{26}$ To address this structural problem, a more diverse senior team could prevent discrimination against women in surgery favouring their hiring and promotion.

Finally, personality traits and behaviours adopted by surgeons are often perceived differently depending on a surgeon's gender, which can have significant impact on an individual's confidence and self-reflection. Respondents to this survey noted being labelled as ruthless in order to succeed (2\%), pressured to 'pull their weight like a man' $(2 \%)$ and admitted a lack of confidence in their ability $(5 \%)$. Women excel in some areas more typically difficult for their male counterparts, including communication, collaboration and patient centredness. ${ }^{27}$ Recent analysis of over 100000 surgical patients in Canada found that those who were operated on by female surgeons were less likely to die 1 month after their procedure,${ }^{28}$ mirroring a previous study according to which female internal medicine doctors had slightly lower rates of death within 30 days of initial hospitalisation. ${ }^{29}$ The authors' possible explanation is that the barriers women face in the surgical environment act as a higher bar to achieve a consultant or leadership role when compared with their male counterparts. Those data need adequate dissemination among healthcare professionals and general population, as in our survey the glass ceiling for women is also represented by nurses and patients (7\%).

This study builds on the global commitment for greater female representation and support in STEM. The greatest challenge currently faced, in the opinion of the authors, is the realisation and elimination of unconscious bias existing in surgery. Gender equity is a leadership issue: when more women are in leadership positions, organisations offer employees more generous policies to support workplace gender ${ }^{30} 31$ and produce better business results. ${ }^{32}$ 
Cultural change requires a nucleus of organisational catalysts who are insiders with outsiders' cultural beliefs. ${ }^{33}$ In today's workplace, these are colleagues at every level of power and leadership acting to call out insults and affronts, eliminate pay and promotion disparities, and advocate for policies that retain a diverse talent pool. Male surgeon colleagues who already mentor and support females are appreciated, but women, also need to step up and promote themselves. ${ }^{34}$ The glass ceiling for women in science is created by people, of either gender, and it can only be broken if all are aware of it and change their behaviour and attitude towards it.

\section{Limitations}

The representativeness and transferability of the results are hindered by the response of the participants to a social media requests through ASGBI, therefore, the findings are reflective of professionals active on social media and might not be representative of the entire female surgical workforce in the UK. Furthermore, those who experienced gender inequalities might have been more likely to answer, or those who were replying may have had recall bias based on the nature of the questions.

Not all participants filled in the free-text boxes and the themes constructed from the written data are the researchers' interpretations of the written responses. Since it was an online survey, it was not possible to probe to gain a deeper understanding of the comments

\section{Recommendations}

The survey posits a current theme of constraints for women working within surgical practice in the UK. The findings should be explored further in National and International Collaborative research for women working in surgery. Interviews and focus groups as methods of data collection would allow participants to speak about their experiences and perspectives in greater detail. A consensus conference, with the guidance and support of regulatory and educational bodies such as ASGBI, could fully explore the barriers faced and work together to produce targeted action plans to address the barriers described.

\author{
Author affiliations \\ ${ }^{1}$ Renal Transplant Directorate, Imperial College Healthcare NHS Trust, London, UK \\ ${ }^{2}$ Science Complex, Faculty of Health Sciences and Wellbeing, University of \\ Sunderland, Sunderland, Sunderland, UK \\ ${ }^{3}$ Directorate of General Surgery, Bariatric Surgical Unit, Sunderland Royal Hospital, \\ Sunderland, Sunderland, UK \\ ${ }^{4}$ Department of General Surgery, University College London Hospital NHS \\ Foundation Trust, London, UK \\ ${ }^{5}$ Directorate of General Surgery, Hepatobiliary-Pancreatic Surgical Services Royal \\ Infirmary of Edinburgh, Edinburgh, UK \\ ${ }^{6}$ Department of Clinical Surgery, University of Edinburgh, Edinburgh, UK \\ ${ }^{7}$ Department of Surgery and Cancer, Imperial College London, London, UK
}

Contributors MIB designed the study, wrote the article, searched the literature and interpreted the data. $\mathrm{CH}$ and YG performed the analysis, wrote the article and interpreted the data. RZ wrote the article and interpreted the data. RP and VP conceptualised the study, wrote the article, interpreted the data and are the senior authors and executive of the ASGBI.
Funding This work was supported by the Association of Surgeons of Great Britain and Ireland (ASGBI).

Competing interests None declared.

Patient consent Not required.

Ethics approval ASGBI Ethical Committee approved this study.

Provenance and peer review Not commissioned; externally peer reviewed.

Data sharing statement The data used to support the findings of this study are included within the article.

Open access This is an open access article distributed in accordance with the Creative Commons Attribution Non Commercial (CC BY-NC 4.0) license, which permits others to distribute, remix, adapt, build upon this work non-commercially, and license their derivative works on different terms, provided the original work is properly cited, appropriate credit is given, any changes made indicated, and the use is non-commercial. See: http://creativecommons.org/licenses/by-nc/4.0/.

\section{REFERENCES}

1. Royal College of Surgeons of England. Statistics. http:// surgicalcareers.rcseng.ac.uk/wins/statistics

2. Taylor KS, Lambert TW, Goldacre MJ. Career progression and destinations, comparing men and women in the NHS: postal questionnaire surveys. BMJ 2009;338:b1735.

3. IET. The Institution of Engeneering and Technology Statistics. https:// www.theiet.org/index.cfm

4. Lavy VSE. On The origins of gender human capital gaps: short and long term consequences of teachers' stereotypical biases. BER Program: Children, Economics of Education, Labor Studies, 2015.

5. Goldacre MJ, Laxton L, Harrison EM, et al. Early career choices and successful career progression in surgery in the UK: prospective cohort studies. BMC Surg 2010;10:32.

6. Hampton T, Greenhalgh R, Ryan D, et al. Female surgical trainee attrition. The Bulletin of the Royal College of Surgeons of England 2016;98:134-7.

7. Villwock JA, Sobin LB, Koester LA, et al. Impostor syndrome and burnout among American medical students: a pilot study. Int $\mathrm{J}$ Med Educ 2016;7:364-9.

8. Khalil R, Moustafa AA, Moftah MZ, et al. How knowledge of ancient Egyptian Women can influence today's gender role: does history matter in gender psychology? Front Psychol 2016;7:7.

9. Crawford E. Women and the first world war: the work of women doctors ancestors. 2006.

10. Michel R. Subjective personal introspection in action-oriented research Qualitative Research in Organizations and Management. An International Journal 2011;6:6-25.

11. Association of Surgeons of Great Britain and Ireland (ASGBI). Women in Surgery facebook group. https://www.facebook.com/groups/ 1607275052681036/

12. Braun V, Clarke V. Using thematic analysis in psychology. Qual Res Psychol 2006;3:77-101.

13. Salles A, Milam L, Cohen G, et al. The relationship between perceived gender judgment and well-being among surgical residents. Am J Surg 2018;215:233-7.

14. Dzau VJ, Kirch DG, Nasca TJ. To care is human - Collectively confronting the clinician-burnout crisis. N Engl J Med Overseas Ed 2018;378:312-4.

15. Yeo HL, Abelson JS, Symer MM, et al. Association of time to attrition in surgical residency with individual resident and programmatic factors. JAMA Surg 2018;153:511.

16. McNally SA. Surgical training: still highly competitive but still very male. The Bulletin of the Royal College of Surgeons of England 2012;94:53-5.

17. Parsons BA, Blencowe NS, Hollowood AD, et al. Surgical training: the impact of changes in curriculum and experience. J Surg Educ 2011;68:44-51

18. Itum DS, Oltmann SC, Choti MA, et al. Access to paid parental leave for academic surgeons. J Surg Res 2018.

19. Lambert TW, Smith F, Goldacre MJ. Combining parenthood with a medical career: questionnaire survey of the UK medical graduates of 2002 covering some influences and experiences. BMJ Open 2017;7:e016822.

20. Unit EC. About ECU's Athena SWAN Charter. http://www.ecu.ac.uk/ equality-charters/athena-swan/about-athena-swan

21. Perrin A. Social Media Usage 2008-2015. Pew Research Center. 2015. 
22. Bellini MI, Marson L. You cannot be what you cannot see. The journey through surgical training from a female perspective. Journal of the Associations of surgeons of Great Britain and Ireland 2017;50:97-9.

23. Harris CA, Blencowe N, Telem D. Response: "Gender fair language matters?". Annals of surgery 2018.

24. Bellini MI. Women in Surgery ASGBI facebook group: an update. Journal of the Association of Surgeons of Great Britain and Ireland 2017;51:99-101.

25. Wilkes M, Feldman MD. Mentoring clinical trainees: a need for high touch. Lancet 2017;389:135-7.

26. Lambert T, Surman G, Goldacre M. UK doctors and equal opportunities in the NHS: national questionnaire surveys of views on gender, ethnicity and disability. J R Soc Med 2014;107:398-408.

27. Koven S. Letter to a young female physician. $N$ Engl J Med 2017;376:1907-9

28. Wallis CJ, Ravi B, Coburn N, et al. Comparison of postoperative outcomes among patients treated by male and female surgeons: a population based matched cohort study. BMJ 2017;359:j4366.
29. Tsugawa Y, Jena AB, Figueroa JF, et al. Comparison of hospital mortality and readmission rates for medicare patients treated by male vs female physicians. JAMA Intern Med 2017;177:206-13.

30. Philip NC, Matt LH. Working for the woman? Female managers and the gender wage gap. American Sociological Review 2007;72:681-704.

31. Ingram TS P. Institutional and resource dependence determinants of responsiveness to work-family issues. The Acad of Management $J$ 1995;38:1466-82.

32. Hunt DL V, Prince S. Why Diversity Matters. McKinsey \& Company. 2015.

33. Meyerson DTD. Tempered radicals as institutional change agents: the case of advancing gender equity at the University of Michigan. Harvard Journal of Law \& Gender 2007;30.

34. Raymond J. Sexist attitudes: most of us are biased. Nature 2013;495:33-4. 